\title{
SOBRE AS MANEIRAS CIENTÍFICAS DE TRATAR O DIREITO NATURAL
}

HEGEL, George Wilhelm Friedrich. Sobre as maneiras científicas de tratar o direito natural: seu lugar na filosofia prática e sua relação com as ciências positivas do direito. Tradução de Agemir Bavaresco e Sérgio B. Christino. São Paulo: Loyola, 2007. 135 p.

Lucas Roberto Paiva*

O filósofo Georg Wilhelm Friedrich Hegel (1770-1831) é um dos maiores nomes do idealismo alemão. A sua obra Sobre as maneiras científicas de tratar o direito natural: seu lugar na filosofia prática e sua relação com as ciências positivas do direito é um marco que aponta as primeiras concepções propriamente hegelianas e organiza um projeto racional das ciências do espírito e a sua ligação com a ciência prática.

Esse texto de Hegel se dirige a todos que tenham interesse em questões filosóficas, mas principalmente no que se refere à questão do direito natural. A obra tem vários objetivos, dentre eles vale destacar: o discurso do método hegeliano que toma como base a ideia de que a filosofia progride trazendo consigo em seu caminho todo o essencial dos momentos anteriores; uma filosofia que se contradiz e nega outra tem como finalidade colocar que a crítica é o lugar da filosofia, em um momento do espírito; passa-se do que antes era considerado o maior grau, ao grau de subordinado, mas trazendo consigo os momentos que até agora o formaram.

É com base nessa chave de leitura que devemos tomar o artigo de Hegel. As duas doutrinas que mais mediam força em suas perspectivas sobre o direito natural nesse período eram o empirismo e o formalismo. Entre elas havia uma grande lacuna sobre como se deveria pensar e ser colocado o direito natural, pois o empirismo tomava como idênticas as diferenças, e o formalismo negava as diferenças em nome da identidade.

Ambos os pontos de vista deixavam questões abertas em sua doutrina acumulada até o início do século XIX. Tal contradição colocava a necessidade de um sistema científico que pudesse efetivar tanto na forma quanto empiricamente as teorias, e esse é o objetivo de Hegel em sua obra, organizar um sistema orgânico do direito natural.

O sistema científico de Hegel tem como objetivo refutar tanto o formalismo, quanto o empirismo, e isso é feito por meio do aufhebung, ou seja, a negação, a

\footnotetext{
* Graduado em filosofia pela PUC Minas. Mestrando em filosofia pela UFSJ.

E-mail: lucasfilosbh@gmail.com.
} 
conservação e a suprassunção de toda a discussão que se tinha em torno do direito natural desenvolvida de Hobbes a Fichte.

Para isso ocorrer, é necessário que sejam apresentadas todas as inconsistências dessas doutrinas, pois a verdadeira negação ocorre pela apresentação do erro a ele mesmo, fazendo com que este chegue àquilo que lhe falta para estar na verdade, ou seja, a apresentação do erro ao próprio erro é o que faz com que ele chegue à verdade.

Hegel adotará no artigo o método especulativo, enquanto aquele que nega as contradições do direito natural, iluminando as contradições presentes nas perspectivas anteriores, por meio das próprias necessidades colocadas por cada teoria, de maneira que, no fim do seu artigo, o autor terá aplicado o método especulativo.

O livro está subdivido em 4 partes. A primeira faz uma crítica à perspectiva do direito natural pensada com base no empirismo científico. A segunda aponta os erros que a perspectiva formalista comete ao formular suas teorias sobre o direito natural. A terceira apresenta a visão de Hegel sobre o direito natural. E a quarta expõe o sentido do direito positivo tendo em vista a ciência especulativa.

$\mathrm{Na}$ introdução dessa obra, Hegel nota que o direito natural é uma parte da ciência filosófica, mas essa posição se coloca contrária à forma como essa época tomou essa questão, pois as ciências particulares saíram do campo filosófico e tomaram como princípio científico os dados da experiência. Para Hegel, isso resultou na impossibilidade do estatuto de ciência verdadeira dessas ciências particulares, pois elas somente possuem a referência de um conjunto de noções empíricas, se servindo de conceitos dualistas e formais, que distanciam a filosofia da possibilidade de afirmar algo efetivo.

Tendo em vista que não se pode chegar em um sistema verdadeiro tomando por base somente as ciências particulares, Hegel traz a reflexão sobre o direito natural para a filosofia, restaurando os próprios métodos e conteúdos filosóficos.

As ciências particulares produzem verdades parciais, já a filosofia toma como sua todas as verdades da ciência, ou seja, essas verdades parciais são somente uma parte da realidade efetiva devida a sua incompletude, já a filosofia é o que configura o sistema da ciência, conectando e ordenando as verdades por meio de uma necessidade lógica. Assim, a função da filosofia do direito de Hegel será criar o sistema da ordem jurídica, dando necessidade lógica e interna aos seus conceitos.

Essa função já havia sido considerada pelo empirismo e pelo formalismo, mas Hegel considera que elas não haviam feito com o método filosófico correto, pois 
colocavam a existência do indivíduo como sendo categórica e absoluta. Assim, concebiam a vida em sociedade a partir do seu pressuposto do indivíduo, mas por meio desse método não conseguiam dar uma unidade racional (lógica) às ciências jurídicas.

Hegel propõe que o direito natural não deve ser compreendido por meio do indivíduo isolado, mas sim por meio da vida em comunidade, que forma a totalidade orgânica. Para isso, o autor propõe o método especulativo como justificação filosófica, que coloca uma negação ao fato de que as doutrinas empiristas e formalistas são criticadas por tomarem como verdade as determinidades produzidas pelo entendimento, e assim não conseguem compreender a totalidade orgânica.

Propondo o método especulativo por meio de uma justificação histórica, Hegel faz uma exposição de forma ordenada do empirismo, do formalismo e do seu método especulativo.

A primeira parte do seu texto apresenta uma crítica à maneira como os filósofos empiristas tratam o direito natural. Os filósofos empiristas são considerados todos aqueles que tomavam as coisas observáveis como objeto de estudo. Eles descobriam a partir do seu método uma multivariedade de fatos, sendo todos eles de igual valor. Assim, nenhum desses princípios pode ser tomado como critério universal, mas o empirismo elege dentre essa variedade um princípio, e o toma como o principal, constituindo sobre esse fundamento a unidade científica. Contudo, para Hegel, é exatamente esse momento que deve ser negado no empirismo, pois ele deixa de obter a totalidade orgânica.

No empirismo, o princípio racional que deveria unificar varia constantemente. Devido a essa contradição, Hegel observa a necessidade de uma determinação que sobreponha às demais, antes colocadas pelo empirismo, daí surgirá o formalismo, momento em que a consciência buscará uma determinação necessária que ligue todas as demais, contendo em si o essencial de todas as experiências empíricas.

$\mathrm{Na}$ segunda parte, o texto aponta a inadequação da teoria formalista ao pensar o direito natural. A perspectiva formal tem como seus expoentes Kant e Fichte. A crítica dirigida a esses pensadores é que eles ao pensarem a questão do direito natural, cometem o erro oposto ao do empirismo, pois partem de uma pura abstração e não de um fato da realidade. Isso faz com que para darem unidade a esse pensamento vazio, há a necessidade de tomar ao acaso uma determinação finita qualquer, e colocá-la como fundamento da abstração pura. Eles elegem a coerção para isso, contudo a base teórica dos formalistas continua na abstração pura, sem adentrar a efetividade. 
A ciência formalista do direito natural não toma como princípio os fatos jurídicos, a única lei que ela toma como sua é a vontade pura, que não tem determinação alguma, ou seja, ela não possui matéria, sua forma é pura.

A crítica de Hegel aos formalistas inicia com a demonstração de que a lei é apenas um dos lados do movimento dialético que o espírito faz, constantemente, em sua efetivação. A lei visa preencher o múltiplo que o empirismo concebia, a necessidade de que o finito seja superado por algo que seja universal, enquanto uma verdade para todos, mas a abstração que o formalismo faz não consegue abarcar as experiências empíricas, ou seja, o formalismo se fixa na abstração pura, que não adentra a efetividade.

Devido à fixação do formalismo em somente um dos lados da relação dialética, ele não consegue conceber a realidade enquanto passagem do infinito ao finito e por isso se fecha em uma pura abstração. Logo este ponto deve ser negado, pois ele apresenta o erro da teoria formal.

Na terceira parte, Hegel apresenta sua visão do direito natural, que visa dar uma totalidade científica por meio do seu método especulativo. Já tendo nos capítulos anteriores examinado as teorias empiristas e formalistas do direito natural, o autor nega $\mathrm{o}$ que nelas se apresenta como contraditório, mas também conserva o que nelas se mostrou verdadeiro, pois os momentos anteriores são momentos da razão.

Feita a negação e a conservação dos momentos anteriores, Hegel expõe o seu pensamento a partir do estabelecimento de um princípio básico do direito natural, demonstrando como esse princípio pode ser relacionado com um sistema objetivo de direitos e deveres e como são condicionados os direitos e os deveres historicamente pelo costume e a tradição da vida ética particular de um povo.

O princípio básico do direito natural é, para o autor, a ciência filosófica que tem por objeto dar unidade e identificar a necessidade de todas as determinações empíricas. Para demonstrar como esse princípio pode se relacionar com um sistema objetivo de direitos e deveres e como esses são constituídos historicamente pelo costume e a tradição na vida ética particular de um povo, Hegel associa sua teoria ao pensamento político dos gregos antigos, principalmente ao de Aristóteles, no qual há uma conexão necessária entre o direito natural e uma comunidade.

Com isso, constata-se que a vinculação é o princípio básico no qual a natureza formal se conecta a um sistema de direitos e deveres historicamente concreto. Assim, demonstra-se a ligação entre forma e conteúdo, constituindo a eticidade, que é a 
efetivação do conceito desenvolvendo-se pela determinação lógica inserida na própria história dos fatos.

Hegel aponta em seu texto o que caracteriza um povo, ele elege como primeiro fato a unidade interna entre os diferentes indivíduos, o que os leva a uma coexistência pacífica. A segunda característica da existência ética de um povo se deve à oposição de um povo a outros povos e, por fim, a última característica marcante de um povo é a economia, pois os indivíduos formam um sistema de necessidades recíprocas, colocando a necessidade da propriedade e do comércio.

Feitos esses apontamentos, o autor conclui que a ideia de direito é uma infinita fluidez múltipla, concretizando-se em diversos momentos, formando as figuras éticas que constituem o resultado da concretização, ou seja, não se pode compreender a existência do direito natural em si ou imutável, pois sendo em si, ele é vazio. Porém, o verdadeiro revela-se na vida ética de um povo, que é o objeto verdadeiro da filosofia do direito, em que as leis positivas apenas constituem o aspecto formal de cada vida, e o direito natural é a substância ética de um povo, pois cada indivíduo é uma realidade na qual se condensa a realidade de uma nação.

A vida ética absoluta compreende nela a infinitude, pois o sujeito imediatamente singular é imediatamente a essência da vida ética absoluta real. Tendo o indivíduo suas virtudes particulares, ele contribui para a formação da cultura da vida do seu povo, pois as virtudes compõem o domínio moral (subjetivamente vivenciado), já as leis que todos os indivíduos seguem comportam a lei natural (objetivamente vivenciada), ou seja, o direito dito natural é formado pela eticidade de um povo que já se encontra nela.

Da relação entre a moral subjetiva e o direito natural objetivo opera-se a mediação dialética de um povo e seus indivíduos. O processo da formação do sujeito se dá por meio da educação, pois desse processo a moral subjetiva incorpora o direito natural objetivo, transformando o direito vigente e formando a eticidade de um povo. A expressão máxima da vida ética de um povo, para Hegel, é a legislação, quando ela reflita perfeitamente a vida ética de um povo que a segue.

$\mathrm{Na}$ quarta parte Hegel expõe a relação das ciências positivas do direito com a ciência especulativa proposta por ele. Partindo da conclusão do capítulo anterior de que a totalidade ética absoluta nada mais é que um povo, Hegel reconhece o direito como uma mediação necessária para combater o caos advindo da atividade social humana, que precisa constantemente suprir suas necessidades. 
Começando pelo reconhecimento social, o filósofo explica como se constitui a posse da propriedade, pois a constituição pertencente à esfera do direito que permite a posse de se tornar propriedade legal.

O caminho até a formação do direito se dá numa direção verdadeiramente ética, pois o sentido do direito é afirmar a universalidade dos sujeitos particulares, fazendo a mediação, para que seja realizado um reconhecimento recíproco nas relações entre os seres humanos.

Com isso, conclui-se que o papel do direito é conservar as demarcações sociais, com vista a possibilitar a garantia da eticidade absoluta, que é a realização efetiva do conceito de um povo.

Escrito em uma linguagem densa, com termos próprios do autor, citando e debatendo constantemente com pensadores da Grécia antiga à época moderna, Sobre as maneiras científicas de tratar o direito natural: seu lugar na filosofia prática e sua relação com as ciências positivas do direito é uma leitura difícil, que se dirige a filósofos ou interessados na área da filosofia.

Mesmo tendo em vista a difícil compreensão do texto para um público não introduzido na área, o artigo de Hegel é de enorme importância, pois com ele observamos as primeiras concepções propriamente hegelianas a partir do discurso do método de Hegel, que implica a negação, a conservação e a evolução de tudo o que era caro para a doutrina do direito natural desenvolvida de Hobbes a Fichte. E nos possibilita refletir sobre questões do nosso tempo como, por exemplo, tendo em vista o nosso cenário da hegemonia política econômica que coloca o interesse individual como supremo, a ponto de justificar o estado de guerra entre povos de uma mesma nação, há a necessidade de pensarmos em fundamentos que assegurem os direitos coletivos universais, e o texto nos auxilia nessa reflexão nos dando um novo horizonte para pensarmos a questão do direito natural com base em perspectivas da formação de direitos universais. 